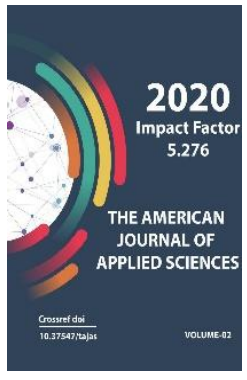

Journal Website: http://usajournalshub.c om/index,php/tajas

Copyright: Original content from this work may be used under the terms of the creative commons attributes 4.0 licence.

\section{Catalytic Synthesis Of Acetone From Acetylene}

Fayzullaev N.I

Samarkand State University, Samarkand, Uzbekistan

Akmalaev K.A

Satbayev University, Almaty, Kazakhstan

Karjavov A

Samarkand State University, Samarkand, Uzbekistan

\title{
ABSTRACT
}

The vapour-phase hydration of acetylene with the formation of acetone on polyfunctional catalysts has been studied. The process parameters have been found that ensure the production of acetone with high selectivity and conversion of acetylene. As a result of studying the effect of temperature on the yield of acetone, it was found that in the temperature range of 360-5000C the dependence between the reaction yield and temperature is extreme and at $4500 \mathrm{C}$ the yield is maximum. Based on the study of the kinetic laws of the reaction, the mechanism of acetone formation in the presence of a given catalyst based on the kinetic equation of the reaction to obtain acetone by the catalytic hydration of acetylene and the results of experimental and qualitative and quantitative compositions of reaction products.

\section{KEYWORDS}

Acetone, acetylene, vapour-phase, hydration, BET equation, diffract meter

\section{INTRODUCTION}

Acetone is a valuable chemical product. It can be obtained by oxidative dehydrogenation of isopropyl alcohol, oxidation of propylene, decomposition of acetic acid and ethyl alcohol, oxidation of cumene, etc. [1-7]. Among the known processes for the production of acetone, the most promising is the synthesis by hydration of acetylene in the presence of catalysts. The advantage of this method is the possibility of carrying out the process in existing installations for the production of acetaldehyde. On the other hand, the process of simultaneous production of acetaldehyde and acetone under the action 
of polyfunctional catalysts and the implementation of the process by flexible technology are promising [8-12].

Currently, the acetic aldehyde is mainly obtained by two methods - hydration of acetylene and oxidation of ethylene [13-17].

The process of hydration of acetylene to acetaldehyde in the presence of catalysts has been studied quite well. Numerous catalysts have been proposed for this process [18-20]. Among the known catalysts for the hydration of acetylene to acetic aldehyde, the most active was the cadmium-calcium-phosphate catalyst (CCP), which is recommended for industrial use [18-21]. However, the cadmiumcalcium-phosphate catalyst is not without its drawbacks. The average output of acetaldehyde per one pass of acetylene does not exceed $7.0 \%$. The CCP catalyst is very sensitive to temperature changes, its service life before regeneration does not exceed 72 76 hours.

Hydration of acetylene in the presence of a catalyst can be carried out in order to obtain acetone. The advantage of this method is the possibility of carrying out the process in existing installations for the production of acetaldehyde. Replacing the cadmiumcalcium-phosphate catalyst with a zinccontaining catalyst makes it possible to obtain acetone with good yield with minor changes in technology.

The production of acetone from acetylene in one phase by passing a mixture of acetylene with steam over catalysts at high temperatures is undoubted of considerable practical and theoretical interest [22].

\section{EXPERIMENTAL PART}

Experiments on the catalytic hydration of acetylene and its derivatives in the gas phase were carried out on a reactor $25 \mathrm{~mm}$ in diameter and $1000 \mathrm{~mm}$ in height, made of stainless steel under stationary conditions. The qualitative and quantitative composition of the reaction products was studied by gasliquid chromatography under the following conditions: stationary phase $15 \%$ Apiezon- $M$ in Cvetochrome, column thermostat temperature $800 \mathrm{C}$, carrier gas flow rate helium $60 \mathrm{~cm} 3 / \mathrm{min}$, detector-DIP. Quantitative analysis was carried out using the method of internal standards [23].

Specific surface area, crushing strength, total pore volume and ash content of the samples were determined.

The specific surface area was determined by the method of thermal desorption of nitrogen in a flow of a carrier gas - helium at the boiling point of liquid nitrogen; the experimental data were processed using the BET equation.

The phase composition of the samples was determined by the method of X-ray diffractometry, the shooting was carried out on a DRON-3M diffract meter on CuKaradiation with a Ni-filter, the length of the $\mathrm{X}$ ray radiation $\lambda=1,54 \stackrel{0}{A}$.

The specific surface area of the obtained catalyst was calculated by the BET method. Dispersed properties of the catalyst were studied using a scanning electron microscope (JSM-6510 LV). The catalytic activity of the obtained sample was studied using the acetylene hydration reaction. Acetaldehyde and acetone were synthesized as follows. Acetylene was saturated with water at a temperature of $70-800 \mathrm{C}$ and at a ratio of water: acetylene $=(1: 3)-(1: 5) \mathrm{mol}$ was passed through the catalyst bed at $3600 \mathrm{C}$ with a space velocity of $180-200$ h-1. The vapour-gas mixture leaving the reactor was cooled in a refrigerator. The reaction products were trapped in water. The catalyst contains acetaldehyde, acetone, crotonaldehyde, paraldehyde, etc. In order to maintain the degree of acetylene conversion at least $80 \%$, the reaction temperature was raised by $100 \mathrm{C}$ every $20 \mathrm{~h}$. After 96-120 hours, the degree of conversion of acetylene decreases to $75-70 \%$. 
Then the reaction was stopped and the catalyst was regenerated in a known manner $[3,4]$.

Subsequently, the effect of various parameters (temperature, space velocity, acetylene-water ratio) on the acetylene conversion and acetone yield was studied. As a result of studying the effect of temperature on the yield of acetone, it was found that in the temperature range of $360-5000 \mathrm{C}$ the dependence between the reaction yield and temperature is extreme and at $4500 \mathrm{C}$ the yield was considered maximum.

Recently, the sol-gel method has been intensively used for the synthesis of inorganic and organo-inorganic matrices at low temperatures. This method has a number of advantages: the simplicity of the used equipment of devices, efficiency, environmental safety, low cost, adaptability of technologies, and others. Nanocatalysts exhibit high catalytic activity, selectivity, stability (stability).

The prospect of using catalysts with nanoparticles in catalysis is associated with two features. First, as the particle size decreases, most of the atoms are located on the surface; therefore, the catalyst consisting of nanoparticles has a large surface and becomes very active in heterogeneous reactions.

Second, most of the properties of nanoparticles are related to their size (size efficiency); therefore, changing the size of nanoparticles can control not only the activity but also the selectivity. As the catalyst particle size decreases, the reaction rate sharply increases.

Based on the foregoing, the study of the possibility of using Nanocatalysts based on the metals $\mathrm{Zn}, \mathrm{Mn}, \mathrm{Fe}, \mathrm{V}$ and other elements with polyfunctional properties for the hydration reaction of acetylene and its derivatives is an urgent task.

Sol-gel technology is one of the methods for producing Nanocatalysts based on the synthesis of inorganic and inorganic-organic hybrid materials from colloidal particles. The use of the sol-gel method in petrochemical synthesis can ensure the production of crystalline nanoparticles and lower the synthesis temperature of a single-phase product. Therefore, at present, studies devoted to the synthesis of Nanocatalysts for petrochemical synthesis are relevant. Proceeding from this, we studied the process of acetylene hydration to obtain acetaldehyde, acetone, or their mixture in the presence of mixed polyfunctional Nanocatalysts [24].

Scheme of the synthesis of nanoparticles with the composition

Fe2O3: $\mathrm{V}_{2} \mathrm{O}_{5}: \mathrm{ZnO}: \mathrm{Mn}_{2} \mathrm{O}_{3}$ with a core-shell structure: 


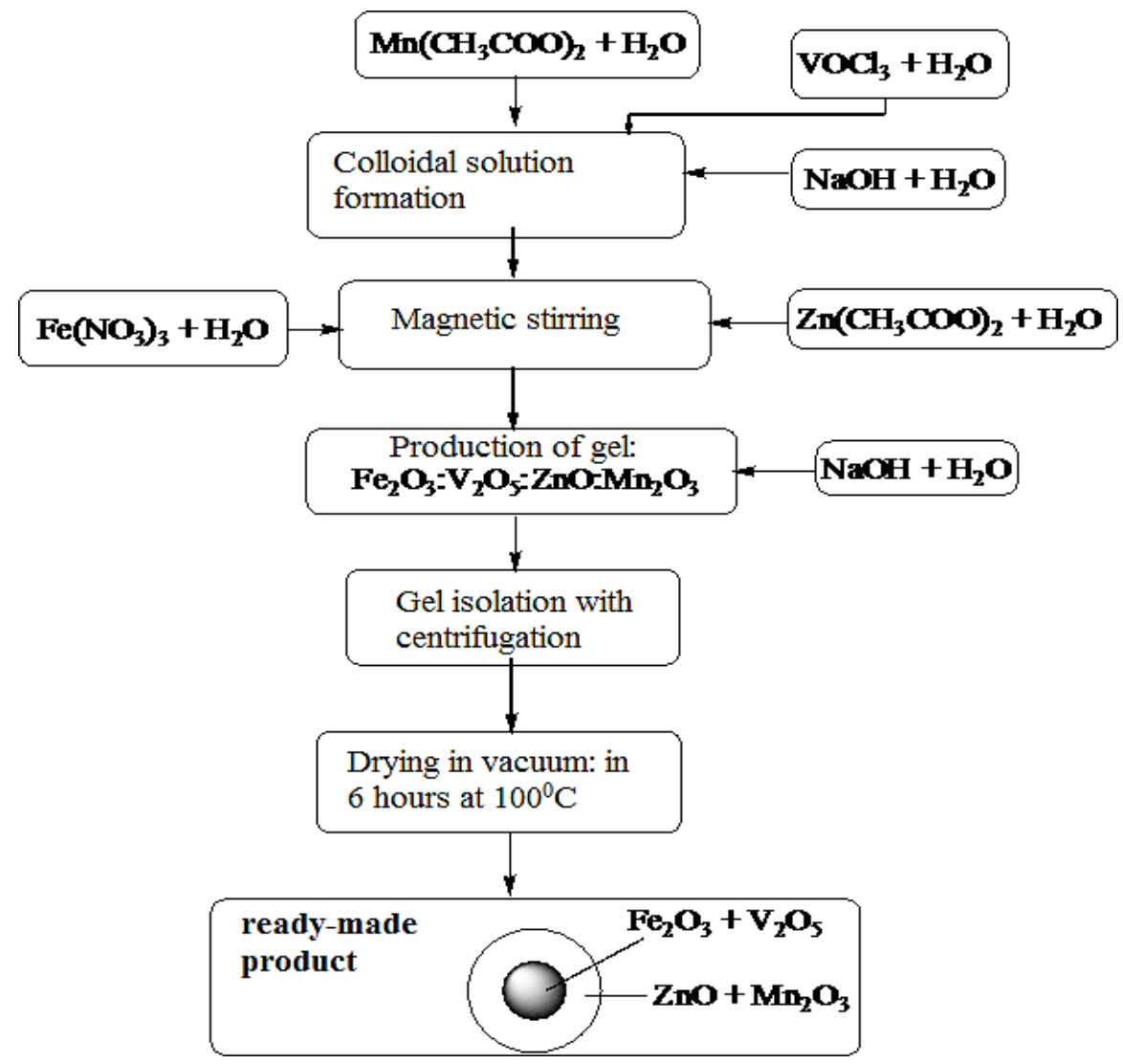

The specific surface area of the obtained catalyst was calculated by the BET method, and the average mesopore size was calculated by the VUA method. The phase composition was studied by X-ray diffraction on a DRON-3 diffract meter (CuKa radiation). Dispersed properties of the catalyst were studied using a scanning electron microscope (JSM-6510 LV). The catalytic activity of the obtained sample was studied using the acetylene hydration reaction.

The reactions of catalytic hydration of acetylene were carried out in a reaction glass tube $2 \mathrm{~cm}$ in diameter, the length of the catalyst layer was $60 \mathrm{~cm}$, and the catalyst volume was $90 \mathrm{~cm} 3$ (the true volume of the catalyst was $25 \mathrm{~cm} 3$ ).

The qualitative and quantitative composition of the reaction products was studied by gasliquid chromatography under the following conditions: stationary phase $15 \%$ Apiezon, $M$ in Cvetochrome, column thermostat temperature $800 \mathrm{C}$, carrier gas flow rate helium $60 \mathrm{~cm} 3 / \mathrm{min}$, detector-DIP. Quantitative analysis was carried out by the method of internal standards.[25]

Subsequently, the effect of various parameters (temperature, space velocity, acetylene-water ratio) on the acetylene conversion and acetone yield was studied.

As a result of studying the effect of temperature on the yield of acetone, it was found that in the temperature range of 360$5000 \mathrm{C}$ the dependence between the reaction yield and temperature is extreme and at $4500 C$ the yield is maximum.

To maintain the conversion of acetylene at a constant level of $80-85 \%$, it is necessary to increase the temperature by $100 \mathrm{C}$ every $15-20$ hours. 
Effect of temperature on reaction yield. The newly formed composition has a high activity and productivity

$\left(\mathrm{Fe}_{2} \mathrm{O}_{3}\right) \mathrm{x} *\left(\mathrm{~V}_{2} \mathrm{O}_{5}\right) \mathrm{y} *(\mathrm{ZnO}) \mathrm{z} *\left(\mathrm{Mn}_{2} \mathrm{O}_{3}\right) \mathrm{k}$ when the effect of temperature on the yield of acetone in the presence of a catalyst was studied, it was found that the optimum temperature for the hydration reaction of acetylene was $4250 \mathrm{C}$ (Table 1).

Table 1.

Effect of temperature on acetylene conversion, acetone yield and process selectivity. (cat $\left(\mathrm{Fe}_{2} \mathrm{O}_{3}\right) \mathrm{x}$ ((V2O5) $\left.\mathrm{y} *(\mathrm{ZnO}) \mathrm{z} *\left(\mathrm{Mn2O}_{3}\right) \mathrm{k}\right)$

\begin{tabular}{|c|c|c|c|c|}
\hline № & $\begin{array}{c}\text { Temperature, } \\
{ }^{0} \mathrm{C}\end{array}$ & $\begin{array}{c}\text { Total conversion of } \\
\text { acetylene, } \%\end{array}$ & $\begin{array}{c}\text { The yield of } \\
\text { acetone, } \\
\%\end{array}$ & Selectivity, S \% \\
\hline 1 & 280 & 18.2 & 10.0 & 54.90 \\
\hline 2 & 330 & 33.5 & 20.6 & 61.2 \\
\hline 3 & 350 & 48.5 & 32.6 & 67.2 \\
\hline 4 & 375 & 52.4 & 41.7 & 73.4 \\
\hline 5 & 400 & 65.8 & 58.5 & 88.9 \\
\hline 6 & 425 & 94.8 & 86.4 & 91.1 \\
\hline 7 & 450 & 86.5 & 70.8 & 81.8 \\
\hline 8 & 475 & 90.8 & 68.4 & 75.3 \\
\hline
\end{tabular}

The table shows that when the temperature reaches $4250 \mathrm{C}$, the yield of acetone is $86.4 \%$, and the selectivity of the process to acetone is $91.1 \%$.

Effect of volumetric velocity on acetylene conversion and acetone yield
The effect of volumetric velocity on acetone yield and acetylene conversion was also studied, and the experimental results are presented in Table 2. As the volume rate of acetylene increases, its overall conversion decreases, as shown in Table 2. 
Table 2.

Effect of volumetric velocity on acetaldehyde yield and acetylene conversion. (cat №4; T=4250C)

\begin{tabular}{|l|l|l|l|}
\hline \multirow{2}{*}{$\begin{array}{l}\text { Volumetric } \\
\text { hour }^{-1}\end{array}$} & velocity & The rotation rate of acetylene, \% & S, \% \\
\cline { 2 - 3 } & General & Acetone & \\
\hline 40 & 98.2 & 34.3 & 34.9 \\
\hline 60 & 97.6 & 44.8 & 45.9 \\
\hline 80 & 96.5 & 55.7 & 57.7 \\
\hline 100 & 95.2 & 68.8 & 72.3 \\
\hline 120 & 94.8 & 86.4 & 91.1 \\
\hline 140 & 92.6 & 69.4 & 74.9 \\
\hline 160 & 90.2 & 50.8 & 56.3 \\
\hline 180 & 87.7 & 38.2 & 43.6 \\
\hline
\end{tabular}

Influence of reagent ratios on acetylene conversion and acetone yield. The effect of $\mathrm{C}_{2} \mathrm{H}_{2}: \mathrm{H}_{2} \mathrm{O}$ mole ratios on acetone yield and acetylene conversion was also studied. The results of the experiment are presented in Table 3.

Table 3. Influence of c2h2: h2o mole ratios on acetone yield.

( $\mathrm{T}=4250 \mathrm{C}$, catalyst №4; )

\begin{tabular}{|c|c|c|c|c|}
\hline \multirow{2}{*}{ № } & \multirow{2}{*}{$\begin{array}{c}\mathrm{C}_{2} \mathrm{H}_{2}: \mathrm{H}_{2} \mathrm{O} \\
\text { ratio mol }\end{array}$} & \multicolumn{2}{|c|}{ Acetylene conversion, \% } & \multirow{2}{*}{$\begin{array}{c}\text { Selectivity } \\
\text { S\% } \\
\end{array}$} \\
\hline & & General & Acetone & \\
\hline 1 & $4: 1$ & 44.8 & 22.3 & 49.8 \\
\hline 2 & $3: 1$ & 65.7 & 46.8 & 71.0 \\
\hline 3 & $2: 1$ & 78.6 & 71.4 & 78.1 \\
\hline 4 & $1: 1$ & 86.2 & 71.8 & 83.3 \\
\hline 5 & $1: 2$ & 94.8 & 86.4 & 91.1 \\
\hline 6 & $1: 3$ & 88.5 & 79.8 & 90.7 \\
\hline 7 & $1: 4$ & 93.4 & 72.5 & 77.6 \\
\hline
\end{tabular}

Kinetic model and mechanism of the catalytic hydration reaction of acetylene. It is known from the scientific literature that there is no single view on the kinetic laws of this process and the mechanism of the process. Therefore, to study the kinetic laws of the catalytic hydration reaction of acetylene, the effect of water and acetylene partial pressures on the rate of acetone formation at a temperature of $400-4750 \mathrm{C}$ in the range of $250 \mathrm{C}$ and $\mathrm{a}$ volumetric velocity (on acetylene) of 120 h-1 was studied.

The effect of the partial pressures of the reagents on the kinetic laws of the process was carried out by changing the partial pressure of one reagent while maintaining the partial pressures of the remaining reagents at a constant rate. In order to keep the linear velocity of the initial mixture constant, the 
required amount of pure argon gas was sent to the reaction zone (field) as needed. The catalyst volume was adjusted accordingly to maintain a constant rate of acetylene flow. As a result of studying the effect of partial pressures of acetylene and water on the kinetic laws of the reaction, it was found that the yield of acetone increases with the decrease of the partial pressure of acetylene. At this time, the total conversion of acetylene increases, while the selectivity of the reaction relative to acetone decreases.

Based on the study of the kinetic laws of the reaction, the following kinetic equation for the reaction of obtaining acetone by the catalytic hydration of acetylene was proposed:

$$
K_{p}=\frac{P_{C_{3} \mathrm{H}_{6} \mathrm{O}} \cdot P_{\mathrm{CO}_{2}} \cdot P_{\mathrm{H}_{2}}^{2}}{P_{\mathrm{C}_{2} \mathrm{H}_{2}}^{2} \cdot P_{\mathrm{H}_{2} \mathrm{O}}^{3}}
$$

The relationship between $\lg K_{p}$ and temperature is expressed as follows:

$$
\lg K p=\frac{17637}{T}-2,611 \lg \mathrm{T}+1,356 \cdot 10^{-3} T-0,092 \cdot 10^{-6} T^{2}-\frac{0,223 \cdot 10^{5}}{T^{2}}-3,794
$$

Based on the results of the experimental and qualitative and quantitative compositions of the reaction products, the following scheme of the mechanism of acetone formation in the presence of a given catalyst is proposed:

The formation of acetone can be expressed in the form of the following sum equation:

$2 \mathrm{C}_{2} \mathrm{H}_{2}+3 \mathrm{H}_{2} \mathrm{O} \rightarrow \mathrm{CH}_{3} \mathrm{COCH}_{3}+2 \mathrm{H}_{2}+\mathrm{CO}_{2}$

The formation of acetylene is explained by the following reliable mechanism: first acetylene is hydrated and acetaldehyde is formed:

$$
\mathrm{C}_{2} \mathrm{H}_{2}+\mathrm{H}_{2} \mathrm{O} \rightarrow \mathrm{CH}_{3} \mathrm{CHO}
$$

Acetaldehyde reacts with water vapour to form acetone:

$2 \mathrm{CH}_{3} \mathrm{CHO}+\mathrm{H}_{2} \mathrm{O} \rightarrow \mathrm{CH}_{3} \mathrm{COCH}_{3}+2 \mathrm{H}_{2}+\mathrm{CO}_{2}$

The formation of acetic acid as a result of the reaction can also be considered as the result of the following reaction:

$\mathrm{CH}_{3} \mathrm{CHO}+\mathrm{H}_{2} \mathrm{O} \rightarrow \mathrm{CH}_{3} \mathrm{COOH}+\mathrm{H}_{2}$
Some of the acetic acid formed is converted to acetone by the release of carbon dioxide and water:

$2 \mathrm{CH}_{3} \mathrm{COOH} \rightarrow \mathrm{CH}_{3} \mathrm{COCH}_{3}+\mathrm{CO}_{2}+\mathrm{H}_{2} \mathrm{O}$

The above method of obtaining acetone is a promising method for Uzbekistan.

\section{CONCLUSION}

The vapour-phase hydration of acetylene with the formation of acetone on polyfunctional catalysts has been studied. The process parameters have been found that ensure the production of acetone with high selectivity and conversion of acetylene. As a result of studying the effect of temperature on the yield of acetone, it was found that in the temperature range of $360-5000 \mathrm{C}$ the dependence between the reaction yield and temperature is extreme and at $4500 \mathrm{C}$ the yield is maximum.

Based on the study of the kinetic laws of the reaction, the mechanism of acetone formation in the presence of a given catalyst based on the kinetic equation of the reaction of 
obtaining acetone by the catalytic hydration of acetylene and the results of experimental and qualitative and quantitative compositions of reaction products.

\section{REFERENCES}

1. Temkin, O.N., Shestakov, G.K., \& Treger, Yu.A. (1991). Acetylene: Chemistry. Reaction mechanisms. Technology. Chemistry.

2. Fayzullaev, N. I., Karjavov, A. R., \& Yusupova, S. S. (2020). Catalytic Synthesis of Acetone Direct Acetylene Hydration. International Journal of Advanced Science and Technology, 29(05), 45074514.

3. Omanov, B. S., Fayzullayev, N. I., \& Xatamova, M. S. (2019). Vinylacetate Production out of acetylene. International Journal of Advanced Research in Science, Engineering and Technology, 6(12).

4. Said, A. E. A. A., Abd El-Wahab, M. M., \& Goda, M. N. (2016). Selective synthesis of acetone from isopropyl alcohol overactive and stable $\mathrm{CuO}-\mathrm{NiO}$ nanocomposites at relatively lowtemperature. Egyptian Journal of Basic and Applied Sciences, 3(4), 357-365.

5. Omanov, B. S., Fayzullaev, N. I., \& Xatamova, M. S. (2020). Vinyl Acetate Production Technology. International Journal of Advanced Science and Technology, 29(3), 4923-4930.

6. Fayzullayev, N., Akmalaiuly, K., \& Karjavov, A. (2020). Catalytic synthesis of a line by acetylene hydration. News of the National Academy of Sciences of the Republic of Kazakhstan, Series chemistry and technology, 2(440), 23-30.

7. Lebedev, N.N. (1988). Chemistry and technology of basic organic and petrochemical synthesis: Textbook. Chemistry.

8. Omanov, B. S., Fayzullaev, N. I., Musulmonov, N. K., Xatamova, M. S., \& Asrorov, D. A. (2020). Optimization of
Vinyl Acetate Synthesis Process. International Journal of Control and Automation, 13(1), 231-238. Fayzullaev, N. I., Yusupov, D., \& Shirinov, X. Sh., Korotoev, AV., Umirzakov, RR.(2002). Catalytic vapour-phase hydration of acetylene and its derivatives. Chemical Industry. N, 7, 1-33.

9. Omanov, B. S., Ibodullayevich, F. N., Anorboevich, E. K., \& Sattorovna, K. M. (2020). Production of vinyl acetate from acetylene. ACADEMICIA: An International Multidisciplinary Research Journal, 10(6), 1031-1038.

10. Fayzullaev, N. I., Akmalaev, K. A., Karjavov, A., Akbarov, H. I., \& Qobilov, E. (2020). Vapour phase catalytic hydration of acetylene. ACADEMICIA: An International Multidisciplinary Research Journal, 10(7), 88-98.

11. Timofeev, V.S., \& Serafimov, L.A. (2003). Principles of the technology of basic organic and petrochemical synthesis: Textbook. manual for universities. Graduate School.

12. Fayzullayev, N. I., \& Turobjonov, S. M. (2015). Catalytic Aromatization of Methane. International Journal of Chemical and Physical Science, 4, 27-34.

13. Karjavov, A. R., Fayzullayev, N. I., \& Musulmonov, N. X. (2020). Jointly Catalytic Synthesis of Vinyl Chloride and Chloroprene from Acetylene. International Journal of Control and Automation, 13(4), 55-62.

14. Omanov, B. S., Fayzullayev, N. I., \& Xatamova, M. S. (2020). Catalytic synthesis of acetylene ut of vinyl acetate and texture characteristics of catalysts. Asian Journal of Multidimensional Research (AJMR). Special Issue, March, 157-164.

15. Wang, Q., Zhu, M., Xu, C., Zhang, H., Wang, X., Dai, B., \& Zhang, J. (2018). ZnCu bimetallic catalysts supported on pure silica MCM-41 for acetylene hydration reaction. New Journal of Chemistry, 42(8), 6507-6514. 
16. Sh, S. B. (2018). Rakhmatov Sh. B., Fayzullayev NI High silicon zeolite preparation from kaolin. Scientific journal of SamSU, 5(109), 106-111.

17. Fayzullayev, N. I. (2019). Kinetics and mechanism of the reaction of the catalytic oxycondensation reaction of methane. Austrian Journal of Technical and Natural Sciences, (5-6).

18. Rakhmatov, S. B., \& Fayzullaev, N. I. (2019). Technology for the production of ethylene by catalytic oxycondensation of methane. European Journal of Technical and Natural Sciences, (5-6), 44-49.

19. Han, S., Shin, K., Henkelman, G., \& Mullins, C. B. (2019). Selective oxidation of acetaldehyde to acetic acid on Pd-Au bimetallic model catalysts. ACS Catalysis, 9(5), 4360-4368.

20. Fayzullaev, N. I., \& Sh, S. B. (2018). Catalytic aromatization of methane with non-mo-contained catalysts. Austrian Journal of Technical and Natural Sciences, (7-8).

21. Fayzullaev, N. I., \& Shukurov, B. S. (2017). Kinetics and Mechanism of the Reaction of Catalytic Dehydroaromatization of Methane. International Journal of Oil, Gas and Coal Engineering, 5(6), 124.

22. Temkin, O. N. (2001). Chemistry of acetylene. "Acetylene tree" in organic chemistry of the XXI century. Soros Educational Journal, 7 (6), 35-38.

23. Temkin, O. N. (1998). Acetylene chemistry. Soros Educational Journal, (12), 52-58.

24. Fayzullaev, N. I., Jumanazarov, R. B., \& Turabjanov, S. M. (2015). Heterogeneous Catalytic Synthesis of Vinyl chloride by Hydrochlorination of Acetylene. IJISETInternational Journal of Innovative Science, Engineering

25. Mukhamadiev, N. Q., Sayitkulov, S. M., Ergashev, I. M., Khafizov, K. F., \& Fayzullaev, N. I. (2003). Optimization of separation on the basis of UNIFAC parameters and evaluation of the composition of the stationary phase in gas-liquid chromatography. Chromatographia, 57(11-12), 831-833. 